\title{
TOPÓI E TRADUÇÃO
}

\author{
Elsa Maria Nitsche Ortiz
}

RESUMO: Dans cet article nous présentons les premières études d'une recherche qui a comme objectif la discussion d'un possible rapport entre les théories de l'enonciation, des topoï et de la traduction. Ici, la traduction est prise comme une activité discursive fondée sur des procédés paraphrastiques - c'est à dire, elle est conçue comme une réformulation (explicative et/ou imitative) d'une activité langagière, étant donné qu'elle met le traducteur em situasion d'interprétation et de reconnaissance des énoncés comme lecteur privilégié et comme co-énonciateur lorsq'il produit le texte em traduction.

PALAVRAS-CHAVE: tradução, enunciação, paráfrase, topói.

Entendo o processo tradutório como uma atividade discursiva plenamente embasada em um processo parafrástico. Dito de outro modo, a tradução só pode existir se for vista como a reformulação, explicativa e/ou imitativa de uma atividade linguageira - em que a enunciação é um elemento constitutivo, pois coloca sujeitos em uma situação de discurso, isto é, de interpretação e de reconhecimento de enunciados pelo tradutor, (como leitor privilegiado) e também como co-enunciador, quando de sua produção do texto já traduzido.

Traduzir, assim, pode ser visto, não só como uma reformulação parafrástica que tem como objetivo maior uma equivalência semântica entre

Elsa Maria Nitsche Ortiz é professora do Instituto de Letras da UFRGS. 
o texto de origem (T) e o texto traduzido (TT), mas também como uma atividade de dimensão discursiva, em que fatores diversos, tais como variabilidade, disponibilidade e perda, estão (presentes) em ação no funcionamento dos enunciados. Em um primeiro momento, à equivalência semântica subjaz a idéia de ser a paráfrase vista como uma relação entre formulações lingüísticas - e, assim, tal momento poderia ser chamado de "paráfrase imitativa", à semelhança da denominação usada por Catherine Fuchs (1994), já que o texto traduzido se apresenta como um substitutivo do texto de origem, ocupando o seu lugar, mas mantendo-lhe ao mesmo tempo, seu estatuto privilegiado de texto-fonte, modelo e original, inserindo, entretanto, o tradutor como co-enunciador. É uma espécie de jogo com a diversidade de formas de expressão - entendendo-se aqui por formas de expressão as inúmeras possibilidades do jogo interlingual (traduzir para as diversas línguas), que exige um domínio especial das línguas em tradução, isto é, dos dois códigos em relação. Esse domínio se materializa, por exemplo, pela captação das diferenças semânticas e estilísticas entre expressões semelhantes, pelo reconhecimento e escolha daquelas possíveis ou impossíveis e, também, mais adequadas ao contexto - daí a necessidade de um grande afinamento qualitativo necessário para que se dê conta, na medida do possível, dos inevitáveis efeitos de sentido.

Traduzir supõe, pois, um trabalho ativo de construção de um texto em um novo suporte lingüístico.

Mas o processo tradutório exige, também, algumas vezes, que reformulações explicativas sejam inseridas no texto traduzido, isso quando o tradutor sente a necessidade de explicitar o sentido para seu futuro leitor-ideal É interessante salientar aqui a formação imaginária do tradutor vis à vis de seu leitor ideal e também vis à vis de si próprio como detentor da "chave" interpretativa do significado de determinada passagem. Tal processo assegura, deste modo, a passagem entre as duas situações da enunciação. Enquanto a atividade tradutória como reformulação imitativa parece pretender anular a distância entre o autor do texto original e o tradutor - que tenta se esconder ao procurar ocupar ficticiamente a situação de produção do texto original - ensejando, assim, um simulacro da enunciação primeira, o uso da paráfrase explicativa faz com que o tradutor ocupe a posição e a função de enunciador único .

$\mathrm{O}$ texto original, entretanto, tem uma força impositiva muito grande; impedindo o tradutor de se situar fora, fazendo-o prisioneiro, levandoo não só a reproduzir o texto, mas também a deformá-lo. O conteúdo e o modo de expressão amalgamam-se entre T e TT.

Ao contrário do processo parafrástico imitativo, o processo parafrástico explicativo exige, entretanto, um distanciamento entre os dois co-enunciadores: o tradutor - sujeito parafraseador reformulador - se 
posiciona em lugar diferente daquele ocupado pelo autor do texto original, o sujeito parafraseado. Todavia a reformulação explicativa só pode ser aceita no processo tradutório como um "auxilio pontual", ajudando na compreensão de itens específicos do texto traduzido. Mas no texto traduzido, esse distanciamento raramente é percebido, pois o leitor de uma tradução não vai ficar procurando provas lingüísticas da inscrição do enunciadortradutor. Esse geralmente consegue se esconder sob construções inseridas do tipo incisas - apostos explicativos, orações relativas, modulações modalizadoras de expressão, etc.

Ao perceber traços lingüísticos no processo parafrástico explicativo em textos traduzidos, comecei a me questionar sobre as necessidades, a razão, o local, a ocasião de tais inserções. Por que, quando, como tais fatos lingüísticos ocorrem? Quais são os problemas contra os quais o tradutor se choca e que desencadeiam o processo explicativo?

Depois de analisar muitas traduções, depois de estudar as mais diversas teorias tradutórias, senti que a solução só poderia ser encontrada com o auxilio de teorias lingüístico-enunciativas. Chegar às teorias da semântica argumentativa foi um salto relativamente fácil. A Teoria da Argumentação na Língua através da Teoria dos Topói, desenvolvida primeiramente por Anscombre e Ducrot ao fazerem uma nova leitura das "Tópicas" aristotélicas, permitiu-me lançar algumas hipóteses quanto ao caso de reformulações explicativas.

Para tentar explicar o itinerário de meu raciocínio, devo voltar a algumas definições essências, tais como:

Topos e seu plural topói relacionam-se, na teoria de Aristóteles, a lugares comuns - crenças apresentadas como comuns a uma certa coletividade da qual fazem parte, no mínimo, o locutor e seu alocutário (Ducrot, 1995).

Angenot (1982, p. 383), em um objetivo didático, reagrupa os principais topói elencados por Aristóteles em três categorias assim designadas: lugares ônticos, lugares axiológicos e lugares deônticos ou práticos. Os primeiros definem as relações entre classes de objetos e as relações de poder de determinações produzidas por operações de subordinação, implicação e oposição, isto é, relações empíricas prováveis. "As segundas introduzem hierarquias de valores que são determinadas a partir das relações entre as classes", aceitando simultânea e indiferentemente valores subjetivos, tendências, ideológicas ou universais. Os lugares práticos "reagrupam regras imperativas do tipo é preciso/não é permitido, decorrentes das relações estabelecidas nos dois primeiro grupos".

Como se pode ver, tal divisão não é isolacionista, pois exige uma interrelação entre os três tipos de lugares comuns. Assim sendo, o topos não é apresentado como uma contribuição, mas como um suporte do dis- 
curso argumentativo (Poitier apud Ducrot, 1995). Dito de outro modo, são encadeamentos argumentativos que "trabalham" independentemente dos conteúdos informativos trazidos pela materialidade lingüística dos enunciados na teoria de Aristóteles. Tais lugares-comuns permitem que se definam as relações entre objetos.

Para Ducrot, usar o discurso é fazer uma "apreensão argumentativa" da situação, isto é, a situação do discurso exige a convocação de um topos que lhe sirva de garantia argumentativa, já que o topos é visto como um argumento geral que pode ser aplicado em situações análogas.

$\mathrm{Na}$ verdade, do agrupamento dos topói proposto por Angenot, só farei uso de uma explicação acerca do critério usado para a definição de topói axiológicos - isto é: os topói axiológicos aceitam os mais diferentes valores - subjetivos, tendenciais, ideológicos ou universais. Tal característica faz-me pressupor que línguas diferentes - códigos de diferentes culturas - podem convocar valores diferentes, topói diferentes. E seria essa diferença que poderia induzir o tradutor a fazer uso de paráfrases explicativas. Quem sabe...

Assim, tendo em vista a reformulação tradutória, procurei caracterizar diferentes topói e suas diferentes materializações lingüísticas, agrupando-os em quatro grandes grupos, tendo em vista as relações que se estabelecem em processos tradutórios, quando da convocação dos mesa- mos pelas diferentes línguas:

topos simétrico: estabelece uma relação simétrica, isto é, as duas culturas em relação tradutória convocam o mesmo topos e a materialização lingüística se faz de maneira semelhante, usando-se, pois, uma reformulação parafrástica imitativa fortemente embasada no calco identidade lexical - (quase uma tradução literal). Como ilustração, posso usar um exemplo caro a Ducrot: "il fait chaud: allons à la plage", cuja reformulação tradutória é: "faz calor: vamos à praia" ou mesmo: "está calor, vamos à praia", uma vez que a relação "tempo quente" leva, sem nenhum estranhamento, a "ir para a praia", em ambas as culb- turas.

topos parcialmente simétrico: o topos convocado é o mesmo, mas materialização na superfície lingüística se faz não através do calco, mas através de outras estruturas lingüísticas, havendo, geralmente, o uso de figuras de linguagem diferentes. Como exemplo, a convocação do topos: "se alguém for viajar e estiver atrasado, perderá o ônibus" é idêntica em francês, entretanto a realização lingüística é bastante diferente: em francês, a expressão metonímica "perder o ônibus"- isto é "perdre l'autobus" é considerada semanticamente paradoxal. Para o espírito francês, em tal situação, "o ônibus não está perdido": o feixe tópico existente em "perder" é garantia de poder ser achado. Em fran- 
cês, a expressão é "rater le départ" havendo em "rater" o feixe tópico de "não atingir o alvo visado". O tradutor / reformulador continua fazendo uso de processo parafrástico imitativo, entretanto não mais bac- seado em um calco.

topos assimétrico: é aquele topos que não é convocado pelo universo da língua em que vai ser feita a tradução. Posso usar como exemplo "Amim pode casar com uma brasileira"/ "Samira não pode casar com um brasileiro" (valho-me dos personagens muçulmanos da novela "O clone", de Glória Pires", exibida pela Rede Globo de Televisão). Para que tal topos seja mais facilmente compreendido, seria necessário que o aqui fictício tradutor usasse uma explicação, facilmente inserida na cadeia lingüística. Essa explicação poderia vir através da inserção de alguma oração, reduzida ou não, do tipo "Alá não permite" ou "Alá aceita outras religiões" - ou algo semelhante. Uma remissão a uma nota ou a um glossário também seria possível. Foi o que ocorreu quando da tradução de "O tempo e o vento", de Érico Veríssimo (1975), para o alemão. O item lexical "Maragato" foi mantido, mas um asterisco remetia a um glossário no fim da tradução. Conduta diferente teve o tradutor da mesma obra para o francês: "Maragato" foi traduzido como "fédéraliste" - uma paráfrase interlingual imitativa, em forma de calco, foi usada. Entretanto o feixe tópico existente em "Maragato" é, em vários aspectos, diferente daquele existente em "fédéraliste". Houve, creio eu, não só uma deformação, como também uma perda.Estratégias semelhantes foram usadas em muitas ocasiões durante todo o processo tradutório da mesma obra. A personagem Ana Terra, ao fazer um parto, exclama: "É mulher", convocando então o par argumentativo "ser mulher / ser inferior, ser destinado a servir aos homens, destinado a sofrer", existente no feixe tópico do item lexical "mulher". Tanto a tradução para o francês quanto para o alemão não conseguiram apresentar realização discursiva semelhante à presente no uso de "mulher" no texto original. A versão alemã limitou-se a uma imitação lexical ("Weib"), salientando, é verdade, o aspecto pejorativo da palavra - mas limitando-se a isso. A versão em francês, por sua vez, deformou completamente o feixe tópico de "mulher", simplificando-o, simplistamente, para "pessoa não adulta do sexo feminino", ao traduzir "É mulher" por "C'est une fille". A presença do determinante ao item lexical "fille" acentua ainda mais a alteração e conseqüente perda do efeito de sentido desejado pelo autor ao acionar tal topos. Considero esse tipo de topos parcialmente assimétrico, pois a assimetria não pode ser considerada como d- total.

topos dissimétrico: As duas línguas colocadas em contato através da relação tradutória podem também, através de uma materialidade lin- 
güística semelhante, convocar curiosamente topói completamente dissociados. Um exemplo do francês e do espanhol poderão lançar alguma luz sobre o que estou me referindo. São as expressões "chansons pour les pieds" e "los pies cantantes" (canções para os pés / os pés cantantes / que cantam). Na estrutura francesa, podemos claramente entender o encadeamento argumentativo realizado pelo topos convocado - isto é : canções atraentes, que atraem $\rightarrow$ levam os pés a sentirem a necessidade de se movimentar ao ritmo proposto pela melodia, a dançarem. Entretanto, pela convocação de um topos para mim desconhecido, o encadeamento proposto por "los pies cantantes" levam a "pies que tienem mal olor". Posso ser levada, por meio de um raciocínio meio esdrúxulo, ao seguinte encadeamento: pés cantantes $\rightarrow$ dançam muito, ficam suados e, conseqüentemente, cheiram mal. Mas já não é um raciocínio meio exagerado? Sou culturalmente incapaz de resolver tal problema! Esses topói, por mim vistos como estabelecendo uma relação tradutória dissimétrica causam, a meu ver, problemas extremamente sérios para um tradutor que, além de bilíngüe não seja também completamente bicultural.

A reformulação tradutória deverá passar pela convocação de um topos semelhante, que terá, entretanto, uma realização lingüística completamente diferente.

Procurei, através deste texto, indicar os novos caminhos que estou começando a trilhar ao tentar usar teorias lingüístico-discursivas para a solução de problemas que, às vezes, parecem colocar o tradutor em "camisas de onze varas".

E agora, como traduzir o topos acima convocado?

\section{BIBLIOGRAFIA}

ANGENOT, Marc. La parole pamphlétarie. Paris; Payot, 1982- p. 383.

DUCROT, Oswald - "Topói et formes topiques". In: ANSCOMBRE (org.). Théorie des topoï. Paris: Kimé, 1995.

FUCHS, Cathérine. Paraphrase et énonciation. Paris: Ophrys, 1994.

VERISSIMO, Érico. O tempo e o vento - O continente. São Paulo: Círculo do Livro, 1975.

. Die Zeit und der Wind. Trad. de Ernst Doblhofer. Stuttgart/Zurich/ Salzburg: Europäische Buchklub, s/d.

. Le temps et le vent - Le continent. Trad. De André Rougon. Paris: Albin Michel, 1996. 